\title{
Humour as a Moderator of Stress and Defence Based Coping Mechanisms among the Youth of Kerala, India
}

\author{
Rinju George ${ }^{1 *}$ and Baby Shari P.A ${ }^{2}$ \\ ${ }^{1}$ Centre for Advanced Research \& Training [CART], CHRIST (Deemed to be University), Bangalore, 560029, \\ Karnataka, India \\ ${ }^{2}$ Department of Psychology, University of Calicut, 673635, Kerala, India
}

\begin{abstract}
The goal of this study was to examine the effect of the moderators of adaptive and maladaptive humour on stress and on the four levels of defence based coping mechanism amongst the youth of Kerala, India. Four hundred and fifty-three youth between the age of 18 and 40, selected from two different cities of North Kerala, India (Calicut, Malappuram) and Central Kerala, India (Cochin, Trissur), were asked to fill out three questionnaires assessing stress, coping and humour. Pearson's test of product-moment correlation indicated that stress had a positive and moderate statistically significant correlation with the first three levels of defence based coping mechanism (pathological defences, immature defences and neurotic defences). Furthermore, there was a positive and weak statistically significant correlation between stress and level-IV coping (mature defences). When positive and moderate correlation-was found for stress with maladaptive humour, no significant correlation was found with adaptive humour. When coping was studied in relationship with humour, a negative and weak statistically significant

ARTICLE INFO

Article history:

Received: 7 March 2019

Accepted: 18 May 2020

Published: 25 December 2020

DOI: https://doi.org/10.47836/pjssh.28.4.04

E-mail addresses:

rinjuhere@gmail.com (Rinju George)

sharipadiyath@yahoo.com (Baby Shari P. A.)

*Corresponding author correlation was found for level-I coping (pathological defences) with adaptive humour, whereas a positive and moderate statistically significant correlation was found with maladaptive humour. Here levelIV coping (mature defences) was found to have a positive and moderate statistically significant relationship with adaptive and maladaptive humour. Moderator analysis
\end{abstract}


showed that maladaptive humour moderated the association between stress and four levels of defence based coping mechanism. The study implied that youth should be trained to use more of mature means of coping and adaptive humour styles in life.

Keywords: Adaptive humour, defence based coping mechanisms, India, Kerala, maladaptive humour stress, youth

\section{INTRODUCTION}

Youth are considered as the greatest wealth and strength of any nation. Many scholars have done extensive studies on youth (Assaad \& Krafft, 2020; Kerestes et al., 2014; Knudson \& Mazurik, 2020; Sugar \& Ford, 2012). Youth across the world, to be very specific Indian youth, receive endless support from the government and various ministries (Joshi \& Kunduri, 2017). Despite all the provision the youth has received from the government, studies indicate that factors like asymmetries on jobs and skills, and the lack of proper guidance for setting realistic career goals hold back young Indians (World Economic Forum, 2018); that is, in the present competitive age, the younger generation is found to be more stressed (Bhargava \& Trivedi, 2018).

Stress is a commonly used word that often refers to the sum of physical, mental and emotional tensions on a person (Marzo et al., 2016). Each person undergoes stress in different forms. Studies on stress have been receiving much research attention including in the domain of children and adolescents
(Reddy et al., 2017; Rentala et al., 2019; Sharrer \& Ryan-Wenger, 2002), youth (Alshagga et al., 2015; Fritz et al., 2017; James et al., 2018) and elderly population (Kumutha et al., 2014; Rani et al., 2016; Tandon, 2017).

One concept, closely linked to stress is coping. A coping mechanism is described as an effort directed to manage stress. This is inclusive of the usage of both task-oriented coping and ego as a defence mechanism (Somaiya et al., 2015). There is an ample number of studies that talk about the significance and application of different coping strategies (Somaiya et al., 2015). The psychoanalytical approach focuses on the use of defence mechanisms as a means toward coping (Freud, 1966). According to the theory, there are four levels of defence mechanisms which include level-I coping (pathological defences), level-II coping (immature defences), level-III coping (neurotic defences) and level-IV coping (mature defences). Vaillant (2011) pointed out that mature defences (e.g., sublimation and humour), as opposed to immature defences (e.g., projection and fantasy), encompassed change in mental health. Further, it was Valliant (1977) who also reported that excessive use of defences by an individual (or use of immature defences by an adult) was linked with psychopathology (as cited in George \& Shari, 2015).

Studies on the stress-buffering effect of humour have been done by many scholars. Work and findings of Fritz et al. (2017) and Mesmer-Magnus et al. (2012) support the stress-buffering effect of humour. However, 
a recent study on bank employees came up with a contradictory finding. According to the study, humour did not act as a stress-buffering agent (Van Oortmerssen et al., 2019). Studies also discussed the positive and negative effects of different humour styles. A study by Abel (2002) found that individuals with high humour appraised less stress, used more positive coping strategies and also reported as having less anxiety than their counterparts. Studies have also found that the adaptive humour (affiliative and self-enhancing humour) resulted in decreased stress and depression and increased level of selfesteem (Kuiper \& McHale, 2009; Nicholas et al., 2004). Moreover, it also functions as an emotion regulation mechanism (Romero \& Pescosolido, 2008). Maladaptive humour, which includes aggressive and self-defeating humour, was reported to lead to increased anxiety, depression and lowers self-esteem and emotional exhaustion (Tumkaya, 2007; Wood et al., 2007). With the strong empirical support on the effects of adaptive and maladaptive humour on the wellbeing of individuals, the present study investigated the effect of adaptive and maladaptive humour on stress-coping relationships.

Based on the empirical data from youth in the Western countries (Abel, 2002; Artemyeva, 2013; Fouladi et al., 2006; Fritz et al., 2017; Nezlek \& Derks, 2001) and the few available studies in the Asian context (Kim, 2014); the present investigation aims at exploring stress, coping and humour among Indian youth and specifically on the youth of Kerala.
Findings of reviewed articles showcased that only limited studies were done on stress, a defence based coping mechanisms and humour in the Indian context (Darshan et al, 2013, as cited in George \& Shari, 2018). On the other side of the spectrum, studies have also reported that the high prevalence of psychological distress among Kerala youth (Jaisoorya et al., 2017) with the increase in the unemployment rate (Baby, 2019). The factors that may lead to college students in Kerala experiencing stress are academic, familial, emotional and work-related issues (Pullokaran, 2018). Meanwhile, highly stressed college students are found to use maladaptive coping styles (Navya et al., 2019). A study on medical officers of Kerala reported stress to be related to numerous coping variables such as denial, substance use, social support, positive reframing, and planning (Sadath \& Kumar, 2017).

As studies specifically on stress, defence based coping mechanism and humour on the youth of Kerala was lacking, investigators decided to explore further on productive youth of Kerala. Hence in this study, we intended to determine the relationship between stress, defence mechanism based coping and humour in a population of youth (ages 18-40) selected from two cities of North Kerala (Calicut, Malappuram) and from two cities of Central Kerala (Thrissur, Cochin). Another purpose of the study was to investigate the moderating role of adaptive and maladaptive humour in stress and coping among the study participants. If humour (adaptive and maladaptive humour) plays a role in between stress and coping 
relationships, it can be concluded that youth needs to develop the skill of using humour in the best way to deal with stressors in life.

\section{Objectives}

1. To examine the relationship among variables of stress, four levels of defence based coping mechanisms, adaptive humour and maladaptive humour among youth.

2. To examine the moderator role of adaptive and maladaptive humour in stress and four levels of defence based coping mechanisms among youth.

\section{Hypotheses}

1. There will be a significant relationship among the variables of stress, four levels of defence based coping mechanisms, adaptive humour and maladaptive humour among youth.

2. Adaptive humour moderates the relationship between stress and four levels of defence based coping mechanisms among youth.

3. Maladaptive humour moderates the relationship between stress and four levels of defence based coping mechanisms among youth.

\section{METHOD}

\section{Participants}

Participants were youth between the ages of 18 and 40 (181 male, 272 female, $\mathrm{N}=453$ ). Survey respondents were recruited from two cities of North Kerala (Calicut, Malappuram) and two cities of Central Kerala (Cochin, Trissur). Respondents were taken from different colleges, universities, IT hubs, small scale industries and companies within the study area. Other than the data collection through questionnaires shared to the respondents in the study area through electronic mail, in-person meetings with few of the participants at their residence were conducted. Details of participants are given in Table 1.

Table 1

Socio-demographic characteristics of the study participants

\begin{tabular}{lll}
\hline & Variables & $\mathrm{n}$ \\
\hline Gender & Male & 181 \\
& Female & 259 \\
& Total & $\mathbf{4 5 3}$ \\
Marital & Married & 194 \\
Status & Unmarried & 259 \\
& Total & $\mathbf{4 5 3}$ \\
\hline
\end{tabular}

\begin{tabular}{lll}
\hline & Variables & $\mathrm{n}$ \\
\hline Age & 18-22 years & 84 \\
23-28 years & 238 \\
29-33 years & 79 \\
34-40 years & 52 \\
Total & $\mathbf{4 5 3}$ \\
\hline
\end{tabular}




\section{Materials}

Data collection was through three different questionnaires. The questionnaires consisted of research instruments that covered three variables namely stress, a defence based coping mechanism and humour. In addition, there were questions on demographic characteristics such as gender, marital status and age of respondents. Stress was measured using Youth Stress Rating Scale (YSRS) developed by George and Shari in 2013 (cited in George \& Shari, 2018). YSRS is a 75 item tool designed to assess the degree of stress experienced, in this case, by the youth of India. Items in this tool are categorized under ten factors: personal, environmental, social, financial, familial, health, intimate relations, job-related, studyrelated and emotional factors. The category of responses ranges from 0 to 5 for varying degrees of stress. A higher score indicated a higher level of stress, and a lower score indicated lower levels of stress. Test-retest reliability $(0.67, \mathrm{P}<0.01)$ and validity of the tool was also established using face validity and content validity. The tool was first constructed in Malayalam, and was later translated to English, before being standardized. Pearson's value of ProductMoment Correlation for the standardization of data was calculated as 0.98 , significant at 0.01 level.

Coping Pattern Inventory-Defence Mechanisms or CPI-DM (George \& Shari, 2013) was used to measure defence based coping mechanisms. CPI-DM consisted of 48 items which were categorized under 16 sub-factors and four different levels. The four levels are level-I coping (pathological defences), level-II coping (immature defences), level-III coping (neurotic defence) and level-IV coping (mature defences). Sub-factors such as denial and delusional projection come under level-I coping (pathological defences). Sub-factors such as passive aggression, fantasy, projection and acting-out come under level-II coping (immature defences). Intellectualization, reaction formation, dissociation, repression and displacement are grouped under level-III of coping (neurotic defences). Sub-factors such as humour, sublimation, suppression, altruism and anticipation come under level-IV coping (mature defences). All the items were positive in nature. Response categories ranged from 1 to 5 .

Test-retest reliabilities for the four coping levels ranged from 0.37 to 0.64 . Test reliability was established using face validity, content validity and criterion validity. Face validity was established using the support of fellow scholars and item analysis technique and content validity was established using theories of coping and defence mechanisms. Criterion validity was established by administering seven subfactors under the Coping Pattern InventoryDefense Mechanisms (CPI-DM) along with the same seven sub-factors from the Defence Style questionnaire (San Martini et al., 2004). The result of correlation ranged from 0.59 to 0.9 . All the results were found to be significant at 0.01 level.

Humour Style Questionnaire-HSQ (Martin et al., 2003) was used to measure 
the two different styles of humour (adaptive and maladaptive humour) exhibited by individuals on various occasions. HSQ consisted of thirty-two items. Response category for the tool ranges from 1 to 7 . For the present study, the investigators changed the response category to a point scale of 1 to 5 for convenience and avoidance of confusion. Internal consistencies of four subscales (affiliative humour, selfenhancing humour, aggressive humour and self-defeating humour) ranges from 0.770 to 0.810 . Test-retest reliability for the four subscales ranges between 0.800 and 0.850 , respectively. Here, four humour dimensions, inclusive of affiliative humour, self-enhancing humour, aggressive humour and self-defeating humour, were correlated with the ratings provided by individuals with people familiar with the HSQ. Moreover, theoretical correlations with significance were construed between various humour scales, self-esteem, hostility, coping, mood, well-being, social relationships and big five models of personality. This tool of measurement, with the application of construct validity, was translated to and standardized in the Malayalam language by George and Shari (2013). Correlation result was found to be $0.609 * *$ for adaptive humour, and $0.755^{* *}$ for maladaptive humour and both the values were found to be significant at 0.01 level.

\section{Procedure}

Primarily, investigators identified two cities from North Kerala (Calicut, Malappuram) and Central Kerala (Thrissur, Ernakulam) for conducting the study. A handful of colleges, universities, IT hubs, small scale industries and companies that came under these four cities were identified and selected for the data collection. Investigators, further, arranged for an in-person encounter with the head of each institution. After getting permission, this study proceeded with meeting the participants who satisfied the age category. Respondents who showed interest in the study were informed about the purpose and nature of the study, along with the assurance of anonymity. The questionnaire was attempted only after asking for their informed consent. Upon the completion, questionnaires were collected with a sense of acknowledgement, and investigators reviewed in avoidance of any missing items in the questionnaires. All the ethical issues underwent direction throughout the process of study.

\section{Data Analysis}

The computation of the basic descriptive statistics (measures of central tendency: mean, median, and mode), availing the SPSS- 21 version, to ensure the normal distribution of the data amongst the study participants. Subsequently, variables of the descriptive statistics were evaluated based on the demographic details (gender, marital status and four age category). Relationships between the study variables was tested using Pearson's ProductMoment Correlation. Since the obtained correlation coefficient (PPMCC) was significant, investigators decided to further proceed with the moderator analysis using 
AMOS software to study the effect of adaptive humour and maladaptive humour (individually) on stress and the four levels of defence based coping mechanisms. A total of eight moderator analysis were computed wherein adaptive humour and maladaptive humour was considered as the moderators. Here stress was considered the independent variable, and four levels of coping (level-I coping-pathological defences, level-II coping-immature defences, level-III copingneurotic defences and level-IV copingmature defences) were considered as the dependent variable.

\section{RESULTS}

\section{Preliminary Analysis}

Preparatory to the inferential statistics, the findings of the basic descriptive statistics were assessed to demonstrate the assumptions of normality. The values from the descriptive statistics, skewness and kurtosis for all the variables are presented in Table 2. The findings of mean, median and mode for study variables are almost similar and values of skewness and kurtosis were approximately close to zero. Hence, the variables studied were normally distributed among the sample population.

Table 2

Description of data for variables of stress, coping and humour

\begin{tabular}{lcclll}
\hline Variables & Mean & Median & Mode & Skewness & Kurtosis \\
\hline YSTRESS & 158.45 & 155 & 111 & 0.16 & -0.88 \\
LEV-I & 10.17 & 10 & 10 & 1.04 & 1.03 \\
Coping & 26.92 & 26 & 25 & 0.44 & 0.25 \\
$\begin{array}{l}\text { LEV-II } \\
\text { Coping }\end{array}$ & 38.82 & 39 & 38 & 0.30 & 0.39 \\
$\begin{array}{l}\text { LEV-III } \\
\text { Coping }\end{array}$ & 44.66 & 45 & 44 & -0.02 & -0.09 \\
$\begin{array}{l}\text { LEV-IV } \\
\text { Coping }\end{array}$ & & & & & \\
ADAPH & 54.41 & 53 & 52 & -0.33 & 2.09 \\
MALH & 40.42 & 41 & 43 & -0.12 & 0.25 \\
\hline
\end{tabular}

Abbreviations: Youth Stress-YSTRESS, Level-I Coping (Pathological defences)-LEV-I Coping, Level-II Coping (Immature defences) - LEV-II Coping, Level-III Coping (Neurotic defences)-LEV-III Coping, LevelIV Coping (Mature defences) - LEV-IV Coping, Adaptive Humour-ADAPH, Maladaptive Humour-MALH 
In addition to that, the comparison of the mean scores was gauged to study the data with respect to marital status, gender and the four different age groups. Details are given in Table 3 and Table 4.

Mean score comparison indicated that stress was high amongst the married counterparts with respect to those unmarried. Concurrently, the findings of all four levels of coping (pathological defences, immature defences, neurotic defences, mature defences) and the two forms of humour (adaptive humour and maladaptive humour) were high among unmarried participants. Gender wise comparison conveys that stress, levels of coping patterns (pathological defences, immature defences, neurotic defences, mature defences) and the maladaptive form of humour was high among males, which was in contrast to the adaptive form of humour being high among the female participants. The age-wise comparison indicated that stress was high among participants in the age group of 34-40 years. Compared to their counterparts, youth in the range of 18-22 years were found to be using varied forms of coping (pathological defences, immature defences, neurotic

Table 3

Descriptive details of variables based on marital status and gender

\begin{tabular}{lcccccccc}
\hline \multirow{2}{*}{$\begin{array}{l}\text { Groups } \\
\text { Variables }\end{array}$} & \multicolumn{9}{c}{ Marital status } & & \multicolumn{3}{c}{ Gender } \\
& \multicolumn{3}{c}{ Married (194) } & \multicolumn{2}{c}{ Unmarried (259) } & Male (181) & \multicolumn{2}{c}{ Female (272) } \\
& Mean & SD & Mean & SD & Mean & SD & Mean & SD \\
\cline { 2 - 9 } Stress & 163.48 & 66.67 & 159.69 & 67.25 & 175.69 & 63.97 & 151.75 & 67.30 \\
Level-I & 9.92 & 2.95 & 10.36 & 3.38 & 10.71 & 3.80 & 9.82 & 2.69 \\
Level-II & 25.93 & 6.30 & 27.67 & 6.54 & 28.76 & 6.59 & 25.70 & 6.14 \\
Level-III & 37.73 & 7.44 & 39.63 & 7.43 & 40.70 & 7.99 & 37.56 & 6.86 \\
Level-IV & 42.62 & 7.51 & 46.19 & 7.99 & 46.26 & 7.72 & 43.59 & 7.97 \\
ADAPTT & 53.40 & 8.65 & 55.17 & 9.38 & 52.99 & 9.01 & 55.35 & 9.06 \\
MALTT & 39.19 & 8.999 & 41.35 & 9.03 & 42.83 & 9.38 & 38.82 & 8.50 \\
\hline
\end{tabular}

Abbreviations: Youth Stress-YSTRESS, Level-I Coping (Pathological defences)-LEV-I Coping, Level-II Coping (Immature defences) - LEV-II Coping, Level-III Coping (Neurotic defences)-LEV-III Coping, LevelIV Coping (Mature defences) - LEV-IV Coping, Adaptive Humour-ADAPH, Maladaptive Humour-MALH 
defences, mature defences) and were also found to be high in participants within the found to be using increasingly adaptive age group of 23-28 years. humour styles. Maladaptive humour was

Table 4

Descriptive details of variables based on four age groups

\begin{tabular}{lcccccccc}
\hline Group & \multicolumn{7}{c}{ Age } \\
\cline { 2 - 9 } & \multicolumn{2}{c}{$\begin{array}{c}18-22 \text { years } \\
(84)\end{array}$} & \multicolumn{2}{c}{$\begin{array}{c}23-28 \text { years } \\
(238)\end{array}$} & $\begin{array}{c}29-33 \text { years } \\
(79)\end{array}$ & \multicolumn{2}{c}{$\begin{array}{c}34-40 \text { years } \\
(52)\end{array}$} \\
\cline { 2 - 9 } Variable & Mean & SD & Mean & SD & Mean & SD & Mean & SD \\
\hline Stress & 157.30 & 67.59 & 158.75 & 66.69 & 167.96 & 65.89 & 169.42 & 69.25 \\
Level-I & 10.62 & 3.41 & 9.96 & 3.08 & 10.42 & 3.19 & 10.04 & 3.46 \\
Level-II & 28.38 & 5.93 & 26.92 & 6.74 & 26.84 & 5.50 & 24.73 & 7.12 \\
Level-III & 40.35 & 7.62 & 38.92 & 7.21 & 37.84 & 7.88 & 37.35 & 7.63 \\
Level-IV & 46.37 & 7.63 & 44.74 & 8.19 & 43.13 & 7.11 & 43.83 & 8.41 \\
ADAPTT & 56.12 & 10.49 & 54.64 & 8.87 & 53.06 & 8.74 & 52.62 & 7.89 \\
MALTT & 41.06 & 9.29 & 41.31 & 8.73 & 39.27 & 8.89 & 37.08 & 9.77
\end{tabular}

Abbreviations: Youth Stress-YSTRESS, Level-I Coping (Pathological defences)-LEV-I Coping, Level-II Coping (Immature defences) - LEV-II Coping, Level-III Coping (Neurotic defences)-LEV-III Coping, LevelIV Coping (Mature defences) - LEV-IV Coping, Adaptive Humour-ADAPH, Maladaptive Humour-MALH

\section{Correlation Between the Variables}

To test the hypothesis- 1 which stated that "there will be a significant relationship among the variables of stress, four levels of defence based coping mechanisms, adaptive humour and maladaptive humour among youth" correlation analysis was performed between the variables (stress, four levels of defence based coping mechanisms, adaptive humour and maladaptive humour). Results of correlation coefficients between all variables are reported in Table 5.
Pearson's Product-Moment correlation test showed that stress had a statistically positive and moderate correlation with first three levels of defence based coping mechanism (level-I coping- pathological defences $(r=.37 * *)$, level-II copingimmature defences $\left(\mathrm{r}=.38^{* *}\right)$ and levelIII coping -neurotic defences $\left(\mathrm{r}=.35^{* *}\right)$. Besides, a positive and weak statistically significant correlation was present between stress and level-IV coping-mature defences $\left(\mathrm{r}=.19^{* *}\right)$. Similarly, the study on stress, in 
its relation to humour, yielded a statistically significant positive and weak correlation with maladaptive humour $(\mathrm{r}=.22 * *)$. These results were alongside negligent significant correlation being obtained with adaptive humour ( $\mathrm{r}=-.-09)$.

When a statistically significant negative and weak correlation was found between level-I coping (pathological defences) and adaptive humour $\left(\mathrm{r}=-.14^{* *}\right)$, a positive and weak statistically significant correlation was found with maladaptive humour $\left(\mathrm{r}=.25^{* *}\right)$. Similarly, findings of level-II coping (immature defences) showed a statistically significant positive and moderate correlation with maladaptive humour $\left(\mathrm{r}=.37^{* *}\right)$, and no significant relation was found with adaptive humour $(\mathrm{r}=-.00)$. When a statistically

Table 5

Pearson's correlation between variables

\begin{tabular}{|c|c|c|c|c|c|c|c|}
\hline Variable & 1 & 2 & 3 & 4 & 5 & 6 & 7 \\
\hline YSTRESS & - & $.37 * *$ & $.38 * *$ & $.35^{* *}$ & $.19 * *$ & -.09 & $.22 * *$ \\
\hline Sig (2-tailed) & & .000 & .000 & .000 & .000 & .067 & .000 \\
\hline LEV-I Coping & & - & $.39 * *$ & $.33 * *$ & $.13 * *$ & $-.14 * *$ & $.25 * *$ \\
\hline Sig (2-tailed) & & & .000 & .000 & .000 & .000 & .000 \\
\hline LEV-II Coping & & & - & $.55^{* *}$ & $.39 * *$ &.- & $.37 * *$ \\
\hline Sig (2-tailed) & & & & .000 & .000 & .951 & .000 \\
\hline LEV-III Coping & & & & - & $.47 * *$ & .09 & $.37 * *$ \\
\hline Sig (2-tailed) & & & & & .000 & .063 & .000 \\
\hline LEV-IV Coping & & & & & - & $.42 * *$ & $.32 * *$ \\
\hline Sig (2-tailed) & & & & & & .000 & .000 \\
\hline ADAPH & & & & & & - & $.34 * *$ \\
\hline Sig (2-tailed) & & & & & & & .000 \\
\hline $\begin{array}{l}\text { MALH } \\
\text { Sig (2-tailed) }\end{array}$ & & & & & & & - \\
\hline
\end{tabular}

$* * p<0.01$

Abbreviations: Youth Stress-YSTRESS, Level-I Coping (Pathological defences)-LEV-I Coping, Level-II Coping (Immature defences) - LEV-II Coping, Level-III Coping (Neurotic defences)-LEV-III Coping, LevelIV Coping (Mature defences) - LEV-IV Coping, Adaptive Humour-ADAPH, Maladaptive Humour-MALH 
positive and moderate correlation was found significant between level-III coping (neurotic defences) and maladaptive humour $(\mathrm{r}=.37 * *)$, no significant relation was found with adaptive humour $(\mathrm{r}=.09)$. Correlation between level-IV coping-mature defences and humour found that level-IV coping has a positive and strong, statistically significant correlation with adaptive humour $(\mathrm{r}=.42 * *)$ and a statistically significant positive and moderate correlation with respect to maladaptive humour $\left(\mathrm{r}=.32^{* *}\right)$. From the above results, it is understood that hypothesis (1) which stated that "There will be a significant relationship among the variables of stress, four levels of defence based coping mechanism, adaptive humour and maladaptive humour among youth" is partially accepted.

\section{Moderator Analysis}

To test the hypothesis (2), which states that "Adaptive humour moderates the relationship between stress and four levels of defence based coping mechanisms among youth", moderator analysis was performed. Here, adaptive humour was applied as the moderator, along with stress and four levels of defence based coping mechanisms were categorized as independent and dependent variables. Table 6 gives the result of moderator analysis.

Table 6

Analysis of the moderator effect of adaptive humour on stress and four levels of defence based coping mechanism

\begin{tabular}{|c|c|c|c|c|c|c|c|c|}
\hline \multirow[t]{2}{*}{ Variables } & \multicolumn{2}{|c|}{$\begin{array}{l}\text { YSTRESS- } \\
\text { ADAPH-LEV-I } \\
\text { Coping }\end{array}$} & \multicolumn{2}{|c|}{$\begin{array}{l}\text { YSTRESS- } \\
\text { ADAPH-LEV-II } \\
\text { Coping }\end{array}$} & \multicolumn{2}{|c|}{$\begin{array}{l}\text { YSTRESS- } \\
\text { ADAPH-LEV-III } \\
\text { Coping }\end{array}$} & \multicolumn{2}{|c|}{$\begin{array}{l}\text { YSTRESS- } \\
\text { ADAPH-LEV-IV } \\
\text { Coping }\end{array}$} \\
\hline & Value & P-value & Value & P-value & Value & P-value & Value & P-value \\
\hline$a=b m x$ & -0.01 & 0.06 & -0.01 & 0.06 & -0.01 & 0.06 & -0.01 & 0.06 \\
\hline $\mathrm{b}=$ bym.x & $-0.04 * *$ & 0.01 & 0.02 & 0.47 & $0.099 * *$ & 0.01 & $0.39 * *$ & $<0.001$ \\
\hline$c=b y x$ & $0.02 * *$ & $<0.001$ & $0.04 * *$ & $<0.001$ & $0.04 * *$ & $<0.001$ & $0.02 * *$ & $<0.001$ \\
\hline$c^{\prime}=$ byx.m & $0.02 * *$ & $<0.001$ & $0.04 * *$ & $<0.001$ & $0.04 * *$ & $<0.001$ & $0.03 * *$ & $<0.001$ \\
\hline $\begin{array}{l}\text { Indirect } \\
\text { effect }\end{array}$ & 0.00 & 0.15 & -0.00 & 0.54 & -0.00 & 0.13 & -0.00 & 0.06 \\
\hline $\begin{array}{l}\text { Sobel } \\
\text { test }\end{array}$ & 1.47 & 0.14 & -0.68 & 0.49 & -1.57 & 0.12 & -1.89 & 0.06 \\
\hline
\end{tabular}

$* * p<0.01$

Abbreviations: Youth Stress-YSTRESS, Level-I Coping (Pathological defences)-LEV-I Coping, Level-II Coping (Immature defences) - LEV-II Coping, Level-III Coping (Neurotic defences)-LEV-III Coping, LevelIV Coping (Mature defences) - LEV-IV Coping, Adaptive Humour-ADAPH, Maladaptive Humour-MALH 
Table 6 provides the output of moderator analysis performed for adaptive humour found in the relationship between stress and four levels of defence based coping mechanism. For the findings of the moderator analysis to be significant, all the values and the results of the Sobel test, along with all of the other values should be significant. The value of ' $a$ ' signifies the relationship between the independent variable and the moderator variable. The relation between the moderator and the dependent variable is denoted with value ' $b$ '. Value 'c', with the inclusion of the moderator, signifies the relationship between the independent and the dependent variable. Indirect effect signifies the extent of change in the dependent variable, when the independent variable is held fixed with a change in the moderator variable, which, in turn, changes the results of the independent variable. The results from the Sobel test signifies whether the inclusion of a moderator variable has resulted in a significant change in the relationship between the independent variable and dependent variable.

Findings from Table 6 shows that only values of $b(-0.04 * *), c(0.02 * *)$ and c' $\left(0.017^{* *}\right)$ were significant when the moderator effect of adaptive humour was studied within the relationship between stress and level-I coping (pathological defences). Concerning the level-II coping (immature defences), only the values of $\mathrm{c}$ $(0.04 * *)$ and c' $(0.04 * *)$ were significant. However, for level-III coping (neurotic defences), the values of b (0.099), c $(0.04 * *)$ and c' $(0.04 * *)$ were significant.
Furthermore, it was found that only values of b $\left(0.39^{* *}\right)$, c $(0.02 * *)$ and c' $(0.03 * *)$ were found significant when it came to the factors of stress and level-IV coping (mature defences). Analyzing the result from the table above, it is clear that not all values are significant. An impact can be created on the relationship between the independent variable and the dependent variable, with the inclusion of the moderator, only when all the values are significant.

In accordance with the result, there is no moderator effect with adaptive humour between stress and four levels of defence based coping mechanism. Here, we accept the null hypothesis and fail to support the alternative hypothesis (2) which states the following: 'adaptive humour moderates the relationship between stress and four levels of defence based coping mechanism among youth'.

Moderator analysis was performed and computed between variables to test the hypothesis (3) that stated: "Maladaptive humour moderates the relationship between stress and four levels of defence based coping mechanisms among youth". In this case, maladaptive humour was lodged as moderator; and stress, along with the four levels of coping mechanisms were considered to be the independent and the dependent variables respectively. Table 7 gives the result of moderator analysis.

From Table 7, it is clear that values of a, b, c, c', are significant based on the results from the indirect effect and Sobel test in all the analysis. In all the cases, the value of c' is less than that of c, and could be 
Table 7

Analysis of the moderator effect of maladaptive humour on stress and four levels of defence based coping mechanism

\begin{tabular}{|c|c|c|c|c|c|c|c|c|}
\hline \multirow[t]{2}{*}{ Variables } & \multicolumn{2}{|c|}{$\begin{array}{l}\text { YSTRESS- } \\
\text { MALH-LEV-I } \\
\text { Coping }\end{array}$} & \multicolumn{2}{|c|}{$\begin{array}{l}\text { YSTRESS- } \\
\text { MALH -LEV-II } \\
\text { Coping }\end{array}$} & \multicolumn{2}{|c|}{$\begin{array}{l}\text { YSTRESS- } \\
\text { MALH -LEV-III } \\
\text { Coping }\end{array}$} & \multicolumn{2}{|c|}{$\begin{array}{l}\text { YSTRESS- } \\
\text { MALH -LEV-IV } \\
\text { Coping }\end{array}$} \\
\hline & Value & P-value & Value & P-value & Value & P-value & Value & P-value \\
\hline $\mathrm{a}=\mathrm{bmx}$ & $0.03 * *$ & $<0.001$ & $0.03 * *$ & $<0.001$ & $0.03 * *$ & $<0.001$ & $0.03 * *$ & $<0.001$ \\
\hline $\mathrm{b}=\mathrm{bym} \cdot \mathrm{x}$ & $0.06 * *$ & $<0.001$ & $0.22 * *$ & $<0.001$ & $0.25 * *$ & $<0.001$ & $0.26 * *$ & $<0.001$ \\
\hline $\mathrm{c}=$ byx & $0.02 * *$ & $<0.001$ & $0.04 * *$ & $<0.001$ & $0.04 * *$ & $<0.001$ & $0.03 * *$ & $<0.001$ \\
\hline $\mathrm{c}^{\prime}=\mathrm{byx} . \mathrm{m}$ & $0.01 * *$ & $<0.001$ & $0.03 * *$ & $<0.001$ & $0.03 * *$ & $<0.001$ & $0.01 * *$ & 0.0073 \\
\hline $\begin{array}{l}\text { Indirect } \\
\text { effect }\end{array}$ & $0.00 * *$ & 0.0020 & $0.01 * *$ & $<0.001$ & $0.01 * *$ & $<0.001$ & $0.01 * *$ & $<0.001$ \\
\hline Sobel test & $3.12 * *$ & 0.0018 & $3.98 * *$ & 0.0001 & $3.98 * *$ & 0.0001 & $3.85 * *$ & $<0.001$ \\
\hline
\end{tabular}

$* * p<0.01$

Abbreviations: Youth Stress-YSTRESS, Level-I Coping (Pathological defences)-LEV-I Coping, Level-II Coping (Immature defences) - LEV-II Coping, Level-III Coping (Neurotic defences)-LEV-III Coping, LevelIV Coping (Mature defences) - LEV-IV Coping, Adaptive Humour-ADAPH, Maladaptive Humour-MALH

interpreted as a reduction in the relationship between stress and level-II coping (immature defences), with the inclusion of maladaptive humour. From the results obtained, it could be explained as a possibility in the change in the relationship between stress and all four levels of coping when maladaptive humour comes in between stress and four levels of coping. In all of the case scenarios, as the value of c' value is less than that of the variable $\mathrm{c}$, it could be perceived as a weakening between the relations of stress and coping when maladaptive humour intervenes. With this results, we fail to accept the null hypothesis and; thereby, support the alternative hypothesis (3) that stated that maladaptive humour moderates the relationship between stress and four levels of defence based coping mechanism among youth.

\section{DISCUSSION}

The current study was conducted to explore the moderator effect of adaptive and maladaptive humour in the relationship between stress and four levels of defence based coping mechanism among the youth of Kerala. Correlation analysis 
performed indicated a moderate and positive correlation between stress and the first three levels of defence based coping mechanism (pathological defences, immature defences and neurotic defences). Thus, the greater amount of stress experienced is related to increase in use of pathological defences (refusing to accept reality, projecting the cause of their life issues to unnatural forces), immature defences (expressing their aggression towards others indirectly, dreaming a lot and who attribute the cause of their problem to others) and neurotic defences (focusing on an intellectual component of a problem, converting unacceptable impulses to opposite ones, trying to maintain good boy image, blocking dangerous thoughts to come to conscious level) amongst the participants of the study and vice versa.

The weak positive correlation found between stress and level-IV coping-mature defences piqued the particular interest in this study. Thus, greater experience of stress was not related to the increased use of mature defences (anticipating and planning about future, engaging in helping behaviour, converting unacceptable impulses to creative work, yoga and other extracurricular activities, doing things after prioritizing and also being humorous in life) among the study participants. This result keeps up with many of the previous findings, wherein the highly stressed individuals use more maladaptive coping styles (Navya et al., 2019). Similar findings that support the present study results in those people with decreased levels of stress to be reported to use more adaptive coping methods (Wang et al., 2005) and those with an increase in their use of adaptive coping show decrease in acculturative stress (Belizaire \& Fuertes, 2011).

When stress was studied in relation to humour, stress showed a weak positive correlation with maladaptive humour. Thus, greater levels of stress are associated with greater use of maladaptive humour (selfdefeating and aggressive humour). This finding is supported from the results reported by Wood et al. (2007) and Tumkaya (2007) showing maladaptive humour (aggressive and self-defeating humour) could lead to increased anxiety, depression and lowers self-esteem and emotional exhaustion. The lack of significant correlation of stress with adaptive behaviour was unexpected. This is in keeping with the findings of Martin et al., (2003) who found that the adaptive component of humour (affiliative and self-enhancing humour) resulted in decreased stress and that it is beneficial for psychosocial well-being. Therefore, it is possible that no significant correlation was found between stress and adaptive humour in the present study. The reason for this could be the youth using adaptive humour style for making new friends, increasing their self-esteem and regulating emotions rather than dealing with stress. Kuiper and McHale (2009), and Romer and Pescosolido (2008), to provide an instance, found that adaptive humour (affiliative and selfenhancing humour) resulted in increased self-esteem and; thereby, functioned as a regulatory mechanism for emotions. 
When coping was studied in relation to humour, level-I coping (pathological defences) showed a negative and weak relationship with adaptive humour. It also provided a positive and weak relationship with maladaptive humour. Thus, increased use of pathological defences was associated with decreased use of adaptive humour (affiliative and self-enhancing humour) and increased use of maladaptive humour (self-defeatingand aggressive humour). When level-II coping and level-III coping showed a positive relation with maladaptive humour, no significant relation was found with adaptive humour. Considering levelIV coping, both adaptive and maladaptive humour had a significant positive relationship, i.e., greater use of immature and neurotic defences were associated with greater use of maladaptive humour. Similarly, greater use of level-IV coping (mature defences) was associated with greater use of both adaptive humour (selfenhancing and affiliative humour) and maladaptive humour (self-defeating and aggressive humour). Studies, supporting the findings, were identified. According to LaBelle et al. (2013) and Abel (2002), individuals with an increased sense of humour were identified as using more positive appraisals and problem-solving coping strategies. A greater sense of humour was also found to result in better coping.

Moderator analysis performed showed that only maladaptive humour moderated the association between stress and four levels of defence based coping mechanism. Thus, greater use of maladaptive humour resulted in a decreased usage of different coping mechanisms when observed under stress. Another unexpected finding from this study was that adaptive humour did not show any significant influence under stress and coping relationship; thereby, indicating the role of maladaptive humour in helping a person to cope with various stressors. This result is in keeping with many previous findings which focused on the moderating role of humour. According to Wood et al. (2007), maladaptive humour (aggressive and self-defeating humour) lead to increased anxiety, depression and lowers self-esteem and emotional exhaustion whereas adaptive humour (affiliative and self-defeating humour styles) moderated the relationship between social anxiety and depressive symptoms (Tucker et al., 2013). Positive humour was found to result in greater coping efficacy, reduced relationship stress, depression and increased relationship satisfaction and self-esteem (Kuiper \& McHale, 2009; Vela et al., 2013). All the studies are supportive evidence for the present findings, but none actually focused on the Indian youth, specifically on the youth of Kerala and the moderating role of two types of humour on the stress and coping relationship. Hence, the study result is a new opener to the research community.

\section{CONCLUSION}

Present investigation finds a positive and moderate statistically significant correlation between stress and the first three levels of defence based coping mechanism (pathological defences, immature defences 
and neurotic defences). When a moderate positive correlation was found for stress with maladaptive humour, no significant correlation was found with adaptive humour. When a negative and weak statistically significant correlation was found for level-I coping (pathological defences) with adaptive humour, a positive and statistically moderate and significant correlation was found with maladaptive humour. Here, level-IV coping (mature defences) was found to have a positive and moderate statistically significant relationship with adaptive and maladaptive humour. Moderator analysis showed that only maladaptive humour moderated the association between stress and four levels of defence based coping mechanism. The result of the study suggests that people who are working with youth group should train youth, specifically the youth from Kerala, India, to provide better and mature means of coping and adaptive humour styles, in order to control the use of immature means of coping mechanism and maladaptive humour styles as it can create negative effects on them.

\section{ACKNOWLEDGEMENT}

Authors would like to thank all the young participants who actively contributed to the study.

\section{REFERENCES}

Abel, M. H. (2002). Humour, stress, and coping strategies. Humour-International Journal of Humor Research, 15(4), 365-381.

Alshagga, M. A., Nasir, N. Z. M., Behzadnia, A., Jasamai, M., Al-Absi, A., \& Al-Dubai, S. A.
R. (2015). Perceived stress and sources of stress among pharmacy students in Malaysian public and private universities: A comparative study. Pharmacy Education, 15(1), 64-68.

Artemyeva, T. V. (2013). Humour as a form of coping behaviour among Russian students. Middle East Journal of Scientific Research, 16(3), 348-351.

Assaad, R., \& Krafft, C. (2020). Excluded generation: The growing challenges of labor market insertion for Egyptian Youth. Journal of Youth Studies. doi: 10.1080/13676261.2020.1714565

Baby, J. (2019). Entrepreneurial ecosystem: Opportunities and challenges among youth with special reference to Thrissur District, Kerala. International Journal of Research in Advent Technology, 7(3), 940-944. doi: 10.32622/ ijrat.73201909

Belizaire, L. S., \& Fuertes, J. N. (2011). Attachment, coping, acculturative stress, and quality of life among Haitian immigrants. Journal of Counseling \& Development, 89(1), 89-97.

Bhargava, D., \& Trivedi, H. (2018). A study of causes of stress and stress management among youth. IRA-International Journal of Management \& Social Sciences, 11(03), 108-117. doi: 10.21013/ jmss.v11.n3.p1

Fouladi, R. T., Rew, L., \& Horner, S. D. (2006). Comparison of three modes of measuring stress, coping, and humour in school-age children. Journal of Nursing Measurement, 14(2), 79-98.

Freud, A. (1966). The ego and the mechanisms of defence. New York, USA: International Universities Press.

Fritz, H. L., Russek, L. N., \& Dillon, M. M. (2017). Humor use moderates the relation of stressful life events with psychological distress. Personality and Social Psychology Bulletin, 43(6), 845-859.

George, R., \& Shari, B. (2013). Coping pattern inventory-defense mechanisms: Psychological 
moderators of stress coping mechanisms among young adults (Unpublished Doctoral thesis), University of Calicut, India.

George, R., \& Shari, B. (2015). Stress and coping patterns in emerging adulthood-An exploration. International Journal in Management and Social Science, 3(2), 426-438.

George, R., \& Shari, B. (2018). Stress among youth-A scientific inquiry. The International Journal of Indian Psychology, 6(1), 54-66. doi: $10.25215 / 0601.028$

Jaisoorya, T. S., Rani, A., Menon, P. G., Jeevan, C. R., Revamma, M., Jose, V., ... Thennarasu, K. (2017). Psychological distress among college students in Kerala, India-Prevalence and correlates. Asian Journal of Psychiatry, 28, 28-31.

James, P., Jamshed, S., Elkalmi, R., AlShami, A., Nor, A., Kabir, F., ... Shamsudin, S. (2018). Causes of stress and management approaches among undergraduate pharmacy students: Findings from a Malaysian public university. Archives of Pharmacy Practice. Available from https://opus. lib.uts.edu.au/handle/10453/131612

Joshi, B., \& Kunduri, E. (2017). Youth in India: Prospects and challenges. n.p.: Centre for Policy Research. Available from https://www. researchgate.net/publication/318780350_Youth_ in_India_Prospects_and_Challenges

Kerestes, R., Davey, C. G., Stephanou, K., Whittle, S., \& Harrison, B. J. (2014). Functional brain imaging studies of youth depression: A systematic review. NeuroImage-Clinical, 4, 209-231.

Kim, K. H. (2014). Correlation of stress-coping, humor sense, and adaptation to college of baccalaureate nursing students. The Journal of the Korea Contents Association, 14(3), 301-313.

Knudson, S., \& Mazurik, K. (2020). Seeking stability: A preliminary exploration of Canadian young adults' financial goals. Journal of Youth Studies, $1-20$.
Kuiper, N. A., \& McHale, N. (2009). Humor styles as mediators between self-evaluative standards and psychological well-being. The Journal of Psychology, 143(4), 359-376.

Kumutha, V., Aruna, S., \& Poongodi, R. (2014). Effectiveness of progressive muscle relaxation technique on stress and blood pressure among elderly with hypertension. IOSR Journal of Nursing and Health Science (IOSR-JNHS), 3, $1-6$.

LaBelle, S., Booth-Butterfield, M., \& Weber, K. (2013). Humorous communication and its effectiveness in coping with interpersonal transgressions. Communication Research Reports, 30(3), 221-229.

Martin, R. A., Doris, P. P., Larsen, G., Gray, J., \& Weir, K. (2003). Individual differences in uses of humour and their relation to psychological well-being: Development of the humour styles questionnaire. Journal of Research in Personality, 37(1), 48-75. doi: 10.1016/S00926566(02)00534-2

Marzo, R. R., Rajamanickan, T., Subramaniam, P., Somasundaram, M., Ramamoorthy, S., Lin, S. T. S., \& Hisham, S. A. B. N. (2016). Study of association between psychological stress and depression among undergraduate medical students from Asia Metropolitan (Amu) in Johor Bahru. Texla International Journal of Academic Research, 3(1), 41-51.

Mesmer-Magnus, J., Glew, D. J., \& Viswesvaran, C. (2012). A meta-analysis of positive humor in the workplace. Journal of Managerial Psychology, 27, 155-190. doi: 10.1108/02683941211199554

Navya, C. J., Mathew, M., \& Joshy, V. M. (2019). Perceived stress and coping strategies among firstyear undergraduate medical students: A crosssectional study, Thrissur District, Kerala. Global Journal of Medical Research, 19(4). Available from https://medicalresearchjournal.org/index. php/GJMR/article/view/1760 
Nezlek, J. B., \& Derks, P. (2001). Use of humour as a coping mechanism, psychological adjustment, and social interaction. Humour, 14(4), 395-414.

Nicholas, K., Melissa, G., Catherine, L., \& Gillian, K. (2004). Humour is not always the best medicine: Specific components of sense of humour and psychological well-being. Humour: International Journal of Humour Research, 17(1-2), 135-168. doi: 10.1515/humr.2004.002

Pullokaran, L. J. (2018). Academic stress among college students in Kerala, India. International Journal of Scientific and Research Publications, 8(11), 299-330. doi: 10.29322/IJSRP.8.11.2018. p8335

Rani, M. U., Kumari, B. V., Indira, A., \& Kantha, K. (2016). Level of stress among elderly at selected old age homes in Nellore. International Journal of Applied Research, 2(6), 820-822.

Reddy, J. K., Menon, K., \& Thattil, A. (2017). Understanding academic stress among adolescents. Artha-Journal of Social Sciences, 16(1), 39-52.

Rentala, S., Nayak, R. B., Patil, S. D., Hegde, G. S., \& Aladakatti, R. (2019). Academic stress among Indian adolescent girls. Journal of Education and Health Promotion, 8, 158. doi: 10.4103/ jehp.jehp_116_19

Romero, E., \& Pescosolido, A. (2008). Humor and group effectiveness. Human Relations, 61(3), 395-418.

Sadath, A., \& Kumar, S. (2017). Stress and coping among medical officers in Kerala: A cross-sectional study. Kerala Journal of Psychiatry, 30(2), 79-83.

San Martini, P., Roma, P., Sarti, S., Lingiardi, V., \& Bond, M. (2004). Italian version of the defense style questionnaire. Comprehensive Psychiatry, 45(6), 483-494.
Sharrer, V. W., \& Ryan-Wenger, N. A. (2002). Schoolage children's self-reported stress symptoms. Pediatric Nursing, 28(1), 21-27.

Somaiya, M., Kolpakwar, S., Faye, A., \& Kamath, R. (2015). Study of mechanisms of coping, resilience and quality of life in medical undergraduates. Indian Journal of Social Psychiatry, 31, 19-28.

Sugar, J., \& Ford, J. D. (2012). Peritraumatic reactions and posttraumatic stress disorder in psychiatrically impaired youth. Journal of Traumatic Stress, 25(1), 41-49.

Tandon, M. (2017). Assessment of the level of stress among elderly. International Journal of Home Science, 3(2), 31-33.

Tucker, R. P., Wingate, L. R., O’Keefe, V. M., Slish, M. L., Judah, M. R., \& Rhoades, K.S. (2013). The moderating effect of humour style on the relationship between interpersonal predictors of suicide and suicidal ideation. Personality and Individual Differences, 54(5), 610-615. doi: 10.1016/j.paid.2012.11.023

Tumkaya, S. (2007). Burnout and humor relationship among university lecturers. Humor, 20(1), 73-92.

Vaillant, G. E. (2011). Involuntary coping mechanisms: A psychodynamic perspective. Dialogues in Clinical Neuroscience, 13(3), 366-370.

Van Oortmerssen, L. A., Caniels, M. C., \& Van Assen, M. F. (2019). Coping with work stressors and paving the way for flow: Challenge and hindrance demands, humor, and cynicism. Journal of Happiness Studies, 1-21.

Vela, $\quad$ L. E., Butterfield, M. B., Wanzer, M. B., \& Vallade, J. I. (2013). Relationships among humour, coping, relationship stress, and satisfaction in dating relationships: Replication and extension. Communication Research Reports, 30(1), 68-75. doi: 10.1080/08824096.2012.746224 
Wang, H. F., \& Yeh., M. (2005). Stress, coping and psychological health of vocational high school nursing students associated with a competitive entrance exam. Journal of Nursing Research, 13(2), 106-116. doi: 10.1097/01. JNR.0000387532.07395.0b

Wood, R. E., Beckmann, N., \& Pavlakis, F. (2007). Humor in organizations: No laughing matter. In J. Langan-Fox, C. L. Cooper, \& R. J. Klimoski (Eds.), Research companion to the dysfunctional workplace (pp. 216-231). Cheltenham, England: Edward Elgar.
World Economic Forum. (2018). Here is what young Indians really want from life. Retrieved on August 6, 2020, from https://www.weforum. org/agenda/2018/10/here-s-what-young-indiansreally-want-from-life/ 
